\title{
Tiempo de desarrollo de insectos Calliphoridos de importancia forense, marzo 2011
}

\author{
Rafael Cano, Elizabeth Carrera, Kelly Casana, Marco Villacorta, Shérmany Aronés \\ Morgue Central de Lima, Instituto Medicina Legal, Ministerio Público, Lima, Perú
}

Introducción: El presente examen se desarrolla para corroborar el desarrollo larvario del Calliphorido con respecto a la literatura actual.

Objetivos: Determinar el tiempo de desarrollo de insectos Calliphoridos, de importancia forense, marzo 2011.

Diseño: Experimental, observacional, prospectivo, longitudinal.

Institución: Morgue Central de Lima, Instituto Medicina Legal, Ministerio Público, Lima, Perú.

Material biológico: Insectos adultos Calliphoridos.

Intervenciones: Se utilizó necrotrampas, redes entomológicas, cámaras de crianzas y frascos de cultivo.

Principales medidas de resultados: Medidas de tendencia central, frecuencias.

Resultados: Tiempo de incubación promedio para huevos de Cochliomyia macellaria: 19 horas. En el periodo postembrionario: larvas de estadio I 19 a 28,5 horas, estadio II 33 a 50 horas y estadio III 53 a 85 horas. Longitudes medias promedio: 2,56 mm, 6,89 mm y 12,61 mm para larvas de primer, segundo y tercer estadio, respectivamente. Tiempo de incubación promedio para huevos Sarconesia chlorogaster: 24,50 horas; periodo postembrionario: larvas estadio I 24,5 a 28,5 horas, larvas II 28,5 a 53,83 horas y larvas III 85 a 125 horas. Longitudes medias promedio de 2,84 $\mathrm{mm}, 5,67 \mathrm{~mm}$ y $15,39 \mathrm{~mm}$ para larvas de primer, segundo y tercer estadio, respectivamente.

Conclusiones: El tiempo de incubación promedio para los huevos de Cochliomyia macellaria y Sarconesia chlorogaster fue 19 y 24,5 horas, respectivamente, lo cual concuerda con la bibliografía actual.

Palabras clave: Entomología forense, díptera, Calliphoridae.

\section{Violencia familiar, incidencia. División Clínico Forense de Lima DICLIFOR, febrero 2012}

Kelly Casana, Shérmany Aronés, José Carreño, Jaime Osores, Segundo Yovera, Cleyber Navarro

DICLIFOR, Instituto de Medicina Legal, Ministerio Público, Lima, Perú

Introducción: La violencia familiar es un problema social, de género y de salud pública, que está determinada por la convivencia familiar no legalizada y demarcada por el hacinamiento.

Objetivos: Determinar incidencia de violencia familiar en DICLIFOR, Lima, febrero 2012.

Diseño: Descriptivo, observacional, retrospectivo.

Institución: DICLIFOR, Instituto de Medicina Legal, Ministerio Público, Lima, Perú.

Material de estudio: Certificados médico legales de violencia familiar.

Intervenciones: Base de datos de violencia familiar, incluyendo certificados médico legales completos del sistema informático DICEMEL, febrero 2012.

Principales medidas de resultados: Medidas de tendencia central, frecuencias y porcentajes.

Resultados: En las 6829 atenciones del mes de febrero, 12,3\% (843) fue por violencia familiar. Sexo mujer $632(74,9 \%)$, hombre $211(25 \%)$. Grupo etario 0 a $17,75(8,9 \%), 18$ a $59,717(85,1 \%), 60$ a $+51(6,1 \%)$. Vínculo con el agresor: conviviente $142(16,8 \%)$, esposo(a) $137(16,3 \%)$. Lesión: equimosis $478(56,7 \%)$. Uso de un agente $589(69,9 \%), 2$ agentes: 215 (25,5\%), 3 a + agentes $39(4,6 \%)$.

Conclusiones: El grupo vulnerable de denuncias por violencia familiar correspondió a las mujeres; el vínculo con el agresor, conviviente; grupo etario de 18 a 59 años; equimosis como tipo de lesión; y número de agentes causantes, un agente.

Palabras clave: Violencia familiar, violencia física. 